\title{
Structural, thermal and photocatalytic properties of composite materials $\mathrm{SiO}_{2} / \mathrm{TiO}_{2} / \mathrm{C}$
}

\author{
Karolina Kucio $^{1}$ D $\cdot$ Barbara Charmas $^{1} \cdot$ Sylwia Pasieczna-Patkowska ${ }^{1}$
}

Received: 11 December 2018 / Revised: 30 January 2019 / Accepted: 4 February 2019 / Published online: 19 February 2019

(c) The Author(s) 2019

\begin{abstract}
In the study the mechanochemical treatment procedure was used to prepare composite materials based on $\mathrm{SiO}_{2}$ with the addition of $\mathrm{TiO}_{2}$ and carbon black as a carbon matter. The investigations were carried out at the three rotational speeds 300,500 and $700 \mathrm{rpm}$. Thermal and structural characteristics of the composites were investigated using $\mathrm{N}_{2}$ adsorption, TG/ DTG/DTA, SEM and FT-IR/PAS methods. The photocatalytic properties were evaluated by methylene blue degradation $\left(\mathrm{C}_{\mathrm{o}}=1 \times 10^{-5} \mathrm{~mol} \mathrm{~L}^{-1}\right)$ at $\mathrm{UV}$ light. The obtained results show that the mechanochemical treatment at different rotational speeds causes intensive changes in the porous structure of the obtained materials. Thermal analysis proved that the obtained materials are characterized by significant thermal stability. The obtained composites have comparable photocatalytic properties with pure $\mathrm{TiO}_{2}$ despite the fact that in the composite only $5 \%$ of $\mathrm{TiO}_{2}$ is used.
\end{abstract}

Keywords Mechanochemical treatment $\cdot$ Composites $\cdot$ Structural properties $\cdot \mathrm{TiO}_{2} \cdot$ Photocatalysis

\section{Introduction}

The intensive development of industry caused a rapid increase in environmental pollution ( $\mathrm{Li}$ et al. 2014). Water pollution caused, among others, by the presence of dyes from industry is a mass problem facing humans worldwide. Most often coloured wastewaters are removed from the industry related to the production of rubber, leather, textiles, cosmetics, paper and plastics (Wu et al. 2017; Haque et al. 2011). Many dyes are toxic, cancerogenic and mutagenic to aquatic organisms (O'Neill et al. 1999; Wu et al. 2017). Even a very small amount of dye in water is highly undesirable (Haque et al. 2011).

The use of conventional methods for dyes removal from water, such as ultrafiltration, adsorption and reverse osmosis does not often give satisfactory results (Rajeshwar et al.

Karolina Kucio

karolina.kucio@poczta.umcs.lublin.pl

Barbara Charmas

barbara.charmas@ poczta.umcs.lublin.pl

Sylwia Pasieczna-Patkowska

sylwia.pasieczna@poczta.umcs.lublin.pl

1 Department of Chromatographic Methods, Faculty of Chemistry, Maria Curie-Skłodowska University, Maria Curie-Skłodowska Sq.3, 20-031 Lublin, Poland
2008). Therefore new technologies for wastewater treatment are still being sought. Heterogeneous photocatalysis is included to advanced oxidation processes and plays a significant role in wastewater treatment. (Rajeshwar et al. 2008; Chong et al. 2010). In order to conduct a heterogeneous reaction five steps have to be taken. First, there must be diffusion of reagents to the surface (1). Then the reagents adsorb on the surface (2) and the reaction (3) proceedes on it. After these stages desorption (4) and diffusion (5) of products from the surface take place (Pirkanniemi and Sillanpää 2002; Herrmann 1999).

For photocatalytic degradation of dyes, the semiconductors (for instance metal oxides or metal sulphides) and their composites are often used (Fu et al. 1996; Zhang and Guo 2013; Ghorai et al. 2011). The most commonly used photocatalyst is titanium dioxide. This oxide is characterized by low cost, non-toxicity, chemical stability and long durability (Mills and Le Hunte 1997; Yin et al. 2003; Nakata and Fujishima 2012). It is not hazardous for the environment and humans (Van Gerven et al. 2007). $\mathrm{TiO}_{2}$ occurs in three polymorphic forms in nature: anatase, rutile and brookite (Zhang and Banfield 2000). Most often only anatase and rutile are used as photocatalysts (Yin et al. 2003). $\mathrm{TiO}_{2}$ has a wide band gap (3.2 eV for anatase and 3.0 for rutile) and therefore it is characterized by high photocatalytic activity 
in UV light (Hanaor and Sorrell 2011; Zhao et al. 2010; Zhang et al. 1997).

There are many methods for producing photocatalysts, e.g.: co-precipitation (Martinez-de La Cruz and Garcia Perez 2010; Yu et al. 2009; Zhang et al. 2005), sol-gel (Anderson and Bard 1997; Gao et al. 2009; Wu and Chen 2004; Yu et al. 2000) and hydrothermal methods (Fu et al. 2006; Kim et al. 2007; Yu and Kudo 2006). They are characterized by large consumption of energy and solvents constituting the reaction medium. Photocatalyst preparation processes usually generate high temperatures and pressures and a lot of waste products which can be dangerous for the environment (Molchanov and Buyanov 2001).

One of the methods of obtaining photocatalysts that does not result in environmental hazards is mechanochemistry (Jalalah et al. 2013; Carneiro et al. 2014). It gives the possibility of preparation of high-performance photocatalytic systems and creation of new physicochemical properties of various types of materials (Molchanov and Buyanov 2001). The mechanochemical processes are therefore in line with the principles of green chemistry introduced by Anastas (Anastas and Kirchhoff 2002). The energy generated during the collisions of the grinding balls is so high that it creates new chemical bonds between the substrates. Mechanochemical treatment in high energy mills enables the design of many compounds with different properties, including photocatalytic ones. In addition, it does not require the use of solvents, and thus reduces or completely eliminates the production of waste products (Kucio and Charmas 2018).

The aim of this paper was preparation and characterization of the composite materials characterized by photocatalytic properties using the mechanochemical method. The composites were based on $\mathrm{SiO}_{2}$ (matrix), $\mathrm{TiO}_{2}$ (photocatalytic component) and carbon black (adsorbent). Their applicability was tested using methylene blue in the range of UV light.

\section{Experimental}

\subsection{Materials}

The initial materials used in the research were $\mathrm{TiO}_{2}(\mathrm{POCH}$, Poland), synthetic amorphous $\mathrm{SiO}_{2}$ (SIPERNAT 50, Degussa, Germany) and carbon black (Gryfskand, Poland) as a carbon source.

\subsection{Mechanochemical treatment (MChT)}

The mechanochemical treatment was carried out using a planetary ball mill Pulverisette 7 (Fritsch, Germany). Four series of samples were prepared in the air atmosphere at rotational speeds (300, 500 and $700 \mathrm{rpm}$ ): (1) $\mathrm{TiO}_{2}$ (after
MChT designated as T-300, T-500 and T-700); (2) $\mathrm{SiO}_{2}$ (designated as S-300, S-500 and S-700); (3) $\mathrm{SiO}_{2}$ with the addition of $\mathrm{TiO}_{2}(5 \%)$ (ST-300, ST-500 and ST-700); (4) $\mathrm{SiO}_{2}$ with the addition of $\mathrm{TiO}_{2}(5 \%)$ and carbon black (1\%) (STC-300, STC-500 and STC-700). The mass ratio of the balls to the powder was 23:1 for the $\mathrm{SiO}_{2}$ series, 6.6:1 for the $\mathrm{TiO}_{2}$ series, $22: 1$ for the $\mathrm{SiO}_{2}-\mathrm{TiO}_{2}$ series and 22:1 for $\mathrm{SiO}_{2}-\mathrm{TiO}_{2}-\mathrm{C}$ series. MChT was carried out for $60 \mathrm{~min}$ (four cycles $\times 15 \mathrm{~min}, 5$-min breaks were between the 15 -min cycles). The container $\left(80 \mathrm{~cm}^{3}\right)$ and 250 balls of $5 \mathrm{~mm}$ diameter (total mass of $92.5 \mathrm{~g}$ ) were manufactured from zirconium oxide, $\mathrm{ZrO}_{2}$. During the milling the temperature and pressure values were registered using the EASY GTM software (Fritsch, Germany). After MChT only the T-series had a coarse-grained consistency and the others were fine-grained.

\subsection{Determination of bulk density}

An analytical scale and a measuring cylinder $\left(10 \mathrm{~cm}^{3}\right)$ were used to determine the bulk density $(\rho)$. Approximately $5 \mathrm{~cm}^{3}$ of each of the studied samples was precisely weighed and next the cylinder was tapped ten times against the background to spread the material evenly. Next the volume of the samples was read. The operation was repeated three times. The bulk density was calculated on the basis of the formula 1 :

$\rho=\mathrm{m} / \mathrm{V}$

where $\mathrm{m}$ - the sample weight $[\mathrm{g}], \mathrm{V}-$ the volume of the sample $\left[\mathrm{cm}^{3}\right]$.

\subsection{Nitrogen adsorption/desorption}

In order to determine the structural parameters of the obtained samples, the method of low-temperature nitrogen adsorption/desorption $(77.4 \mathrm{~K})$ was used. The isotherms were recorded using a Micromeritics ASAP 2405N (USA) adsorption analyzer. Based on the obtained data the specific surface area $\mathrm{S}_{\mathrm{BET}}$ (BET equation at $\mathrm{p} / \mathrm{p}_{0}$ between 0.06 and 0.2 , where $\mathrm{p}$ and $\mathrm{p}_{0}$ are the equilibrium and saturation pressures of nitrogen, respectively), the micropore surface $\left[\mathrm{S}_{\text {micro }}\right.$, calculated using the t-plot method (Gregg and Sing $1982)]$, the pore volume $\left(\mathrm{V}_{\mathrm{p}}\right.$, estimated at $\left.\mathrm{p} / \mathrm{p}_{0} \approx 0.98\right)$, the volume of micropores $\left(\mathrm{V}_{\text {micro }}\right)$ and the average pore radius $\left(\mathrm{R}_{\mathrm{av}}\right.$, calculated for the model of cylindrical pores, $\mathrm{D}_{\mathrm{p}}=4 \mathrm{~V}_{\mathrm{por}} / \mathrm{S}_{\mathrm{BET}}$ ) were determined. Pore volume distributions in the function of their sizes were calculated using the Barrett-Joyner-Halenda (BJH) method (Barret et al. 1951). 


\subsection{Determination of macropores volume}

In order to determine the total pores and macropores volumes, the pores of these samples were filled with methanol. The samples were firstly dried at 110 for $24 \mathrm{~h}$ to eliminate the physically adsorbed water. Using a glass analytical burette $\left(\mathrm{V}=1 \mathrm{~cm}^{3}\right)$ small portions of methanol were added to the sample (known mass) and the pores filling process was ultrasound-aided. The pores filling was repeated until they were completely full. The titration procedures was repeated three times. After filling the pores, the volume of methanol consumed for making the pores full in a given weight of the tested material was read. The total pore volume was calculated according to Eq. 2:

$\mathrm{V}_{\text {total }}=\mathrm{V}_{\mathrm{me}, \mathrm{av}} / \mathrm{m}_{\mathrm{s}}$

where $\mathrm{V}_{\text {total* }}$ - the total pores volume $\left[\mathrm{cm}^{3} \mathrm{~g}^{-1}\right], \mathrm{V}_{\mathrm{me}, \mathrm{av}}$ - the average volume of the methanol filling pores $\left[\mathrm{cm}^{3}\right], \mathrm{m}_{\mathrm{s}}$-the sample mass [g].

The volume of macropores $\left(\mathrm{V}_{\text {macro** }}\right)$ was determined from the Eq. 3:

$\mathrm{V}_{\text {macro* }}=\mathrm{V}_{\text {total }}{ }^{*}-\mathrm{V}_{\mathrm{p}}$

where $\mathrm{V}_{\text {total }}$ - the total volume of pores $\left[\mathrm{cm}^{3} \mathrm{~g}^{-1}\right], \mathrm{V}_{\mathrm{p}}$ the volume of sorption pores obtained from the $\mathrm{N}_{2}$ adsorption/desorption data $\left[\mathrm{cm}^{3} \mathrm{~g}^{-1}\right]$.

\subsection{Spectroscopic characteristics}

The Fourier transform infrared photoacoustic spectroscopy (FT-IR/PAS) was used to record the spectra (Bio-Rad Excalibur 3000MX spectrometer, detector MTEC 300). The spectra were recorded in the range $4000-400 \mathrm{~cm}^{-1}$.

\subsection{Thermal analysis}

The thermal studies of the samples were carried out heating in air atmosphere from 20 to $1200{ }^{\circ} \mathrm{C}$ (heating rate $10^{\circ} \mathrm{min}^{-1}$ ) using a Derivatograph C (Paulik, Paulik \& Erdey, MOM, Budapest). The weight of the test samples was about $16 \mathrm{mg}$. The TG-DTG-DTA curves were registered. Ceramic crucibles and $\mathrm{Al}_{2} \mathrm{O}_{3}$ as a reference material were used in the investigations.

\subsection{Photocatalytic test}

The obtained materials were studied for their photocatalytic properties. Methylene blue $\left(\mathrm{C}_{16} \mathrm{H}_{18} \mathrm{ClN}_{3} \mathrm{~S}\right.$, $\mathrm{C}_{\mathrm{o}}=1 \times 10^{-5} \mathrm{~mol} \mathrm{~L}^{-1}$ ) which is a standard dye commonly used in the photocatalytic studies was used. The tests were carried out in a glass reactor (UV-RS-2, Heraeus) under ultra violet radiation. The ratio of sample mass to the solution was $1 \mathrm{mg} / 1 \mathrm{ml}$. The reactor with the test sample was placed on a table with a magnetic stirrer in order to ensure the same distribution of the catalyst in the entire volume of the system. The solution was mixed with the test sample without access to light for $30 \mathrm{~min}$ to determine dye adsorption on the photocatalyst surface. Then the UV light was on. The samples were taken at regular intervals, filtered using syringe filters and centrifuged $(2 \times 15 \mathrm{~min}$, $12,000 \mathrm{rpm})$. Using the UV/VIS spectrophotometer (Helios Gamma, Spectro-Lab, Poland) the solution concentrations were measured based on the calibration curve $\left(y=176.06 x+0.0664, R^{2}=0.9983\right)$.

\section{Results and discussion}

\subsection{Pressure and temperature changes obtained during MChT}

Figure 1 presents an exemplary course of temperature (a) and pressure (b) changes recorded during the mechanochemical preparation of STC composites series. It can be clearly seen that at small rotation $(300 \mathrm{rpm})$ the temperature and pressure values increase systematically in each subsequent cycle. The use of 500 and $700 \mathrm{rpm}$ results in slightly different effects: although the temperature systematically increases after the maximum value in the first cycle the obtained pressures are reduced. This may indicate the highest efficiency of the first grinding cycle at such high rotation speed followed by gradual stabilization of the system. Analyzing the course of the curves in Fig. 1b, it can be seen that the highest pressure values were achieved for the sample subjected to a mechanochemical treatment at $700 \mathrm{rpm}$. However, with the increasing processing time, the temperature of all systems increases. The highest values of the temperature and pressure are obtained for the STC-700 sample (Fig. 1a). Similar courses of the temperature and pressure changes were obtained for all tested materials.

\subsection{Porous structure}

In Fig. 2 the low-temperature $\mathrm{N}_{2}$ adsorption/desorption isotherms (a, c, e, g) and dV/dR (b, d, f, h) curves for the prepared samples are presented. As follows from the analysis of the course of adsorption isotherms they are of type IV according to the IUPAC classification (Rouquerol et al. 1994). The isotherms characterized by poorly developed hysteresis loops (IV type) indicate that the obtained composites are mesoporous materials, in the pores of which the phenomenon of capillary condensation is observed. The course of the analyzed isotherms indicates also a small number of micropores. 

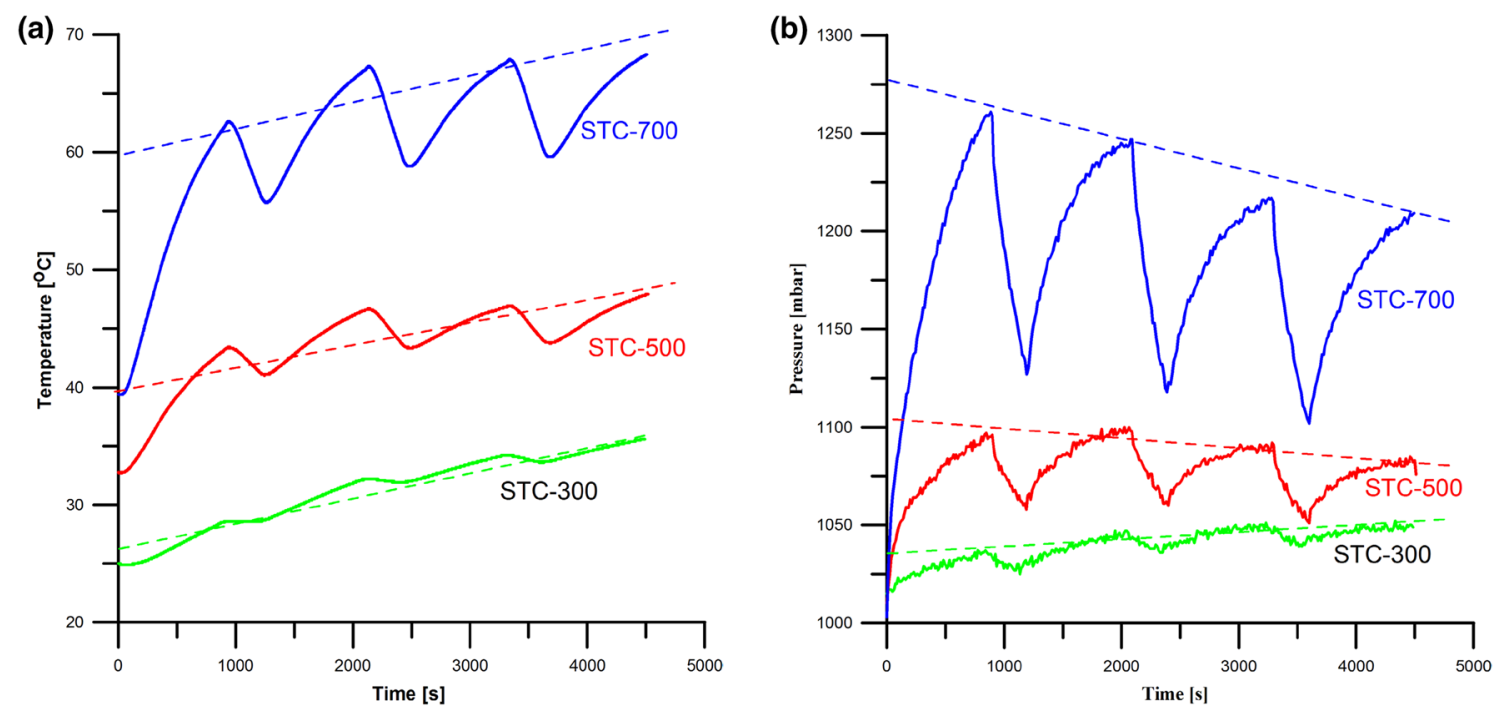

Fig. 1 Exemplary changes of temperature (a) and pressure (b) during the mechanochemical treatment of STC series composite

The analysis of the isotherms shape shows clearly that due to the mechanochemical treatment, the porous structure of all materials including $\mathrm{SiO}_{2}$ is destroyed ( $\mathrm{S}, \mathrm{ST}$ and STC series). This is the most evident during the mechanochemical treatment of initial $\mathrm{SiO}_{2}$ (Fig. 2a) and composites obtained on its base-the ST (Fig. 2e) and STC (Fig. 2g) series. As one can see the MChT at the rotation speed of $300 \mathrm{rpm}$ causes partial lowering of the isotherms. However, the rotation speeds 500 and $700 \mathrm{rpm}$ cause that the isotherms are placed horizontally just above the $\mathrm{p} / \mathrm{p}_{0}$ axis. This suggests an intense reduction in the structural parameters and changes in the porosity. As follows after MChT the $\mathrm{dV} / \mathrm{dR}$ curves for the samples containing $\mathrm{SiO}_{2}$ (S, ST and STC series) have monomodal character and are characterized by narrow mesopores at $R_{\text {dom }}=2 \mathrm{~nm}$ while the $\mathrm{dV} / \mathrm{dR}$ band for $\mathrm{SiO}_{2}$ ini was relatively wide with a maximum at $3 \mathrm{~nm}$. The mechanochemical modification caused the decrease of the pore volume but did not change the dominant pore size which is $\sim 2 \mathrm{~nm}$ (Fig. 2b, f, h). These observations are confirmed by the structural parameters included in Table 1.

The $\mathrm{TiO}_{2}$ ini which had a poorly developed porous structure and the T-300, T-500, T-700 obtained a better developed porous structure than that of $\mathrm{TiO}_{2}$ ini after the mechanochemical treatment (Fig. 2c, d). However, in the case of $\mathrm{SiO}_{2}$ an opposite effect was observed. The isotherms are gradually placed higher relative to the $\mathrm{p} / \mathrm{p}_{0}$ axis which indicates an increase in the porosity of the obtained materials after MChT. These materials (except for T-700) do not have clearly developed dominant pores (Fig. 2d). The bandwidth is wide and the average pore radius is almost $10 \mathrm{~nm}$ (Fig. 2d). Only the T-700 material is characterized by a clearly created peak with the maximum at $\sim 2 \mathrm{~nm}$ indicating the dominant pore radius $R_{\text {dom}}$.
Table 1 presents the structural parameters of composites obtained in the mechanochemical treatment process. The $\mathrm{SiO}_{2}$ milling results in a significant reduction in the specific surface area $\left(\mathrm{S}_{\mathrm{BET}}\right)$ and the surface of micropores $\left(\mathrm{S}_{\text {micro }}\right)$ of the obtained materials. The initial silica has a well-developed surface area $\left(350 \mathrm{~m}^{2} \mathrm{~g}^{-1}\right)$, which after MChT decreases to 236.1 (S-300), 38.1 (S-500) and 27 (S-700) (Table 1). Similar changes are observed for the other parameters included in Table 1, except for bulk density (this parameter increases during the MChT process).

The analysis of the presented data shows that in a series of composites including $\mathrm{SiO}_{2}$ (ST and STC series) obtained by mechanochemical treatment, the highest specific surface area and pore volume are found in the composites obtained at lower revolutions $(300 \mathrm{rpm})$ which is due to the behaviour of the main component, $\mathrm{SiO}_{2}$, whose structure is easily destroyed during the MChT process.

The addition of $\mathrm{TiO}_{2}$ into the structure (ST series) causes a small decrease of $\mathrm{S}_{\mathrm{BET}}$ which is not observed in the case of the $\mathrm{V}_{\mathrm{p}}$ parameter. This results from the contribution of both $\mathrm{SiO}_{2}$ (main component, decreasing the porosity after $\mathrm{MChT}$ ) and $\mathrm{TiO}_{2}$ (additive, increasing this parameter after MChT) in the composite structure. The similar dependences are observed for the STC series but the $\mathrm{S}_{\mathrm{BET}}$ parameters are slightly larger than for the ST series which is a result of the addition of carbon black of a relatively large specific surface area $\left(441.3 \mathrm{~m}^{2} \mathrm{~g}^{-1}\right)$. For the last two series changes of the other parameter are similar to those for $\mathrm{SiO}_{2}$ because of much higher content of $\mathrm{SiO}_{2}$ in them.

Analyzing the data on the initial $\mathrm{TiO}_{2}$, it can be concluded that the material has a poorly developed specific surface area $\left(6.5 \mathrm{~m}^{2} \mathrm{~g}^{-1}\right)$ where almost half $\left(2.6 \mathrm{~m}^{2} \mathrm{~g}^{-1}\right)$ is the micropore surface. The mechanochemical treatment 
Fig. 2 Low-temperature adsorption/desorption isotherms of nitrogen $(\mathbf{a}, \mathbf{c}, \mathbf{e}, \mathbf{g})$ and pore volume distribution functions $\mathrm{dV} / \mathrm{dR}$ regarding their radius $(\mathbf{b}$, $\mathbf{d}, \mathbf{f}, \mathbf{g}$ ) for all samples

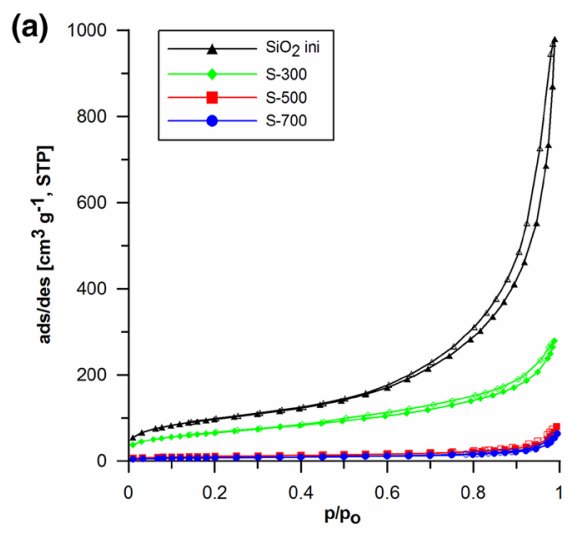

(b)

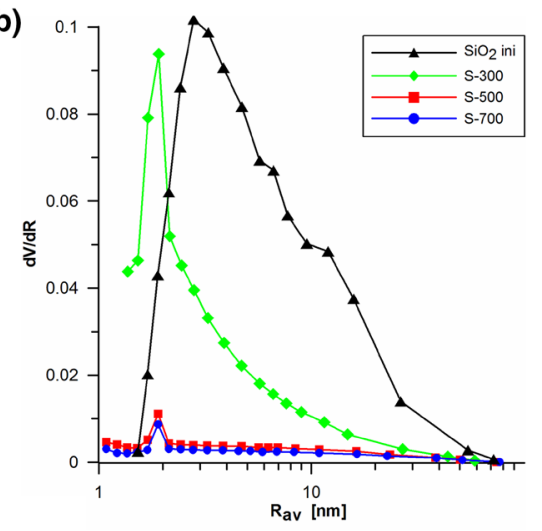

(c)

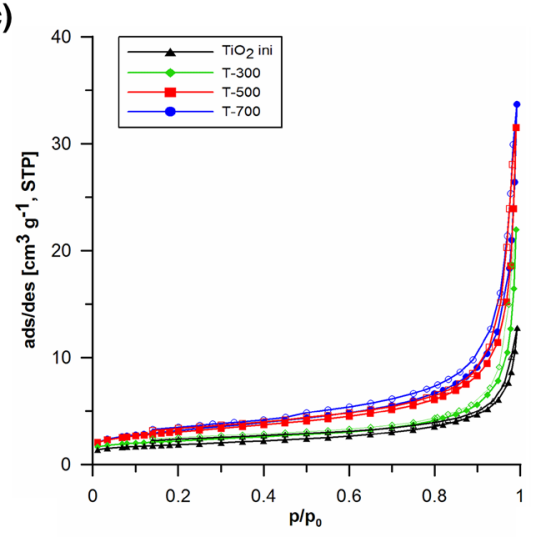

(d)
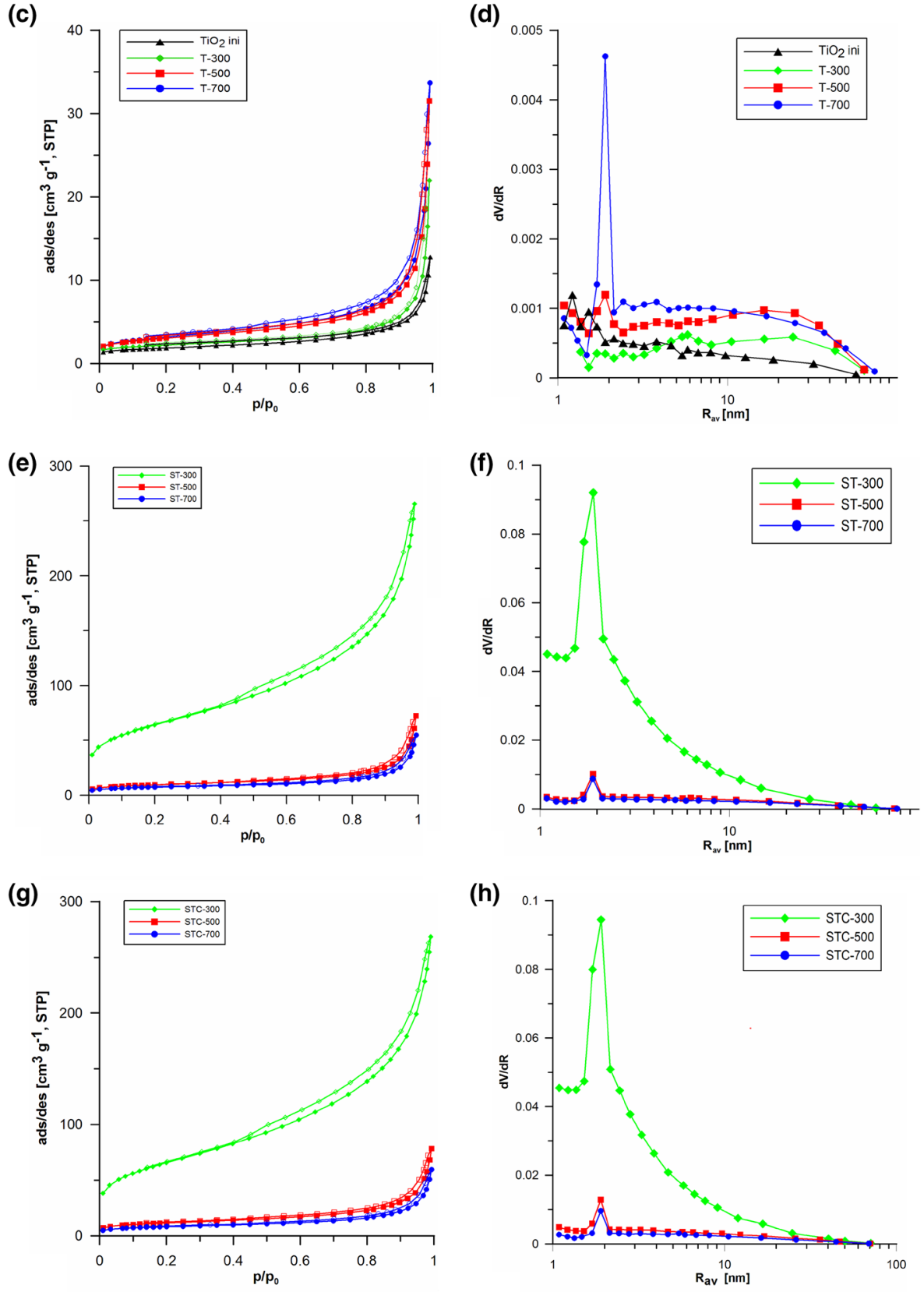

(h)

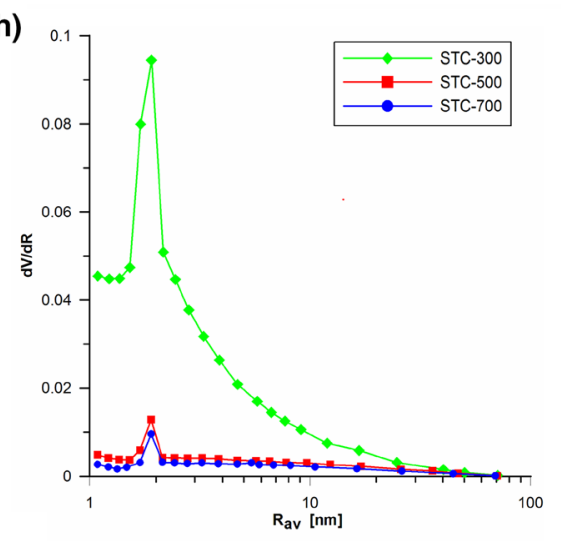


Table 1 Parameters of the porous structure of obtained materials

\begin{tabular}{|c|c|c|c|c|c|c|c|c|c|}
\hline Sample & $\mathrm{S}_{\mathrm{BET}}\left(\mathrm{m}^{2} \mathrm{~g}^{-1}\right)$ & $\mathrm{S}_{\text {micro }}\left(\mathrm{m}^{2} \mathrm{~g}^{-1}\right)$ & $S_{\text {ext }}\left(m^{2} g^{-1}\right)$ & $\mathrm{V}_{\mathrm{p}}\left(\mathrm{cm}^{3} \mathrm{~g}^{-1}\right)$ & $\begin{array}{l}\mathrm{V}_{\text {micro }} \\
\left(\mathrm{cm}^{3} \mathrm{~g}^{-1}\right)\end{array}$ & $\mathrm{R}_{\mathrm{av}}[\mathrm{nm}]$ & $\begin{array}{l}\mathrm{V}_{\text {total* }} \\
\left(\mathrm{cm}^{3} \mathrm{~g}^{-1}\right)\end{array}$ & $\begin{array}{l}\mathrm{V}_{\text {macro* }} \\
\left(\mathrm{cm}^{3} \mathrm{~g}^{-1}\right)\end{array}$ & $\rho\left(\mathrm{g} \mathrm{cm}^{-3}\right)$ \\
\hline $\mathrm{TiO}_{2}$ ini & 6.5 & 2.6 & 3.9 & 0.020 & 0.001 & 6.10 & 0.433 & 0.414 & 0.66 \\
\hline $\mathrm{T}-300$ & 7.7 & 3.3 & 4.4 & 0.034 & 0.001 & 8.77 & 0.466 & 0.432 & 0.99 \\
\hline $\mathrm{T}-500$ & 10.8 & 2.4 & 8.4 & 0.049 & 0.001 & 9.04 & 0.367 & 0.318 & 1.26 \\
\hline $\mathrm{T}-700$ & 11.3 & 1.9 & 9.4 & 0.052 & 0.001 & 9.21 & 0.300 & 0.248 & 1.51 \\
\hline $\mathrm{SiO}_{2}$ ini & 350 & 37.7 & 312.3 & 1.520 & 0.013 & 8.66 & 2.083 & 0.563 & 0.12 \\
\hline S-300 & 236.1 & 23.5 & 212.6 & 0.430 & 0.008 & 3.66 & 1.033 & 0.603 & 0.23 \\
\hline $\mathrm{S}-500$ & 38.1 & 7.3 & 30.8 & 0.122 & 0.003 & 6.45 & 0.483 & 0.361 & 0.42 \\
\hline S-700 & 27 & 4.7 & 22.3 & 0.098 & 0.002 & 7.31 & 0.466 & 0.368 & 0.41 \\
\hline ST-300 & 230.9 & 22.9 & 207.9 & 0.411 & 0.0081 & 3.56 & 1.333 & 0.922 & 0.21 \\
\hline ST-500 & 34.7 & 8.2 & 26.5 & 0.112 & 0.003 & 6.45 & 0.599 & 0.487 & 0.46 \\
\hline ST-700 & 26.6 & 8.2 & 18.5 & 0.085 & 0.003 & 6.37 & 0.483 & 0.398 & 0.40 \\
\hline STC-300 & 236.7 & 28.3 & 208.4 & 0.415 & 0.010 & 3.51 & 1.449 & 1.034 & 0.36 \\
\hline STC-500 & 41.9 & 9.7 & 32.3 & 0.121 & 0.004 & 5.76 & 0.616 & 0.495 & 0.36 \\
\hline STC-700 & 29.1 & 7.2 & 21.9 & 0.092 & 0.003 & 6.34 & 0.533 & 1.774 & 0.45 \\
\hline $\mathrm{C}$ & 441.3 & 106.9 & 334.3 & 0.606 & 0.047 & 2.75 & - & - & - \\
\hline
\end{tabular}

$S_{\text {micro }}$ the specific surface of micropores, $S_{\text {ext }}$ the external surface, $V_{\mathrm{p}}$ the total volume of sorption pores, $V_{\text {micro }}$ the volume of micropores $V_{\text {total* }}$ the total pores volume determined using methanol, $V_{\text {macro* }}$ the macropores volume determined using methanol

of this material increases the specific surface area $\left(\mathrm{S}_{\mathrm{BET}}\right)$ of subsequent composites, however, it is not a significant increase $\left(\mathrm{T}-700, \mathrm{~S}_{\mathrm{BET}}=11.3 \mathrm{~m}^{2} \mathrm{~g}^{-1}\right)$. The observed surface increase in the case of $\mathrm{TiO}_{2}$ results from the considerable fragmentation of the material. The increase in the specific surface area of these samples can be clearly seen also in the SEM images (Fig. 3). $\mathrm{TiO}_{2}$ after the mechanochemical treatment at $700 \mathrm{rpm}$ has clearly sharped edges (Fig. 3b) while the grain edges of T-300 are smooth (Fig. 3a).
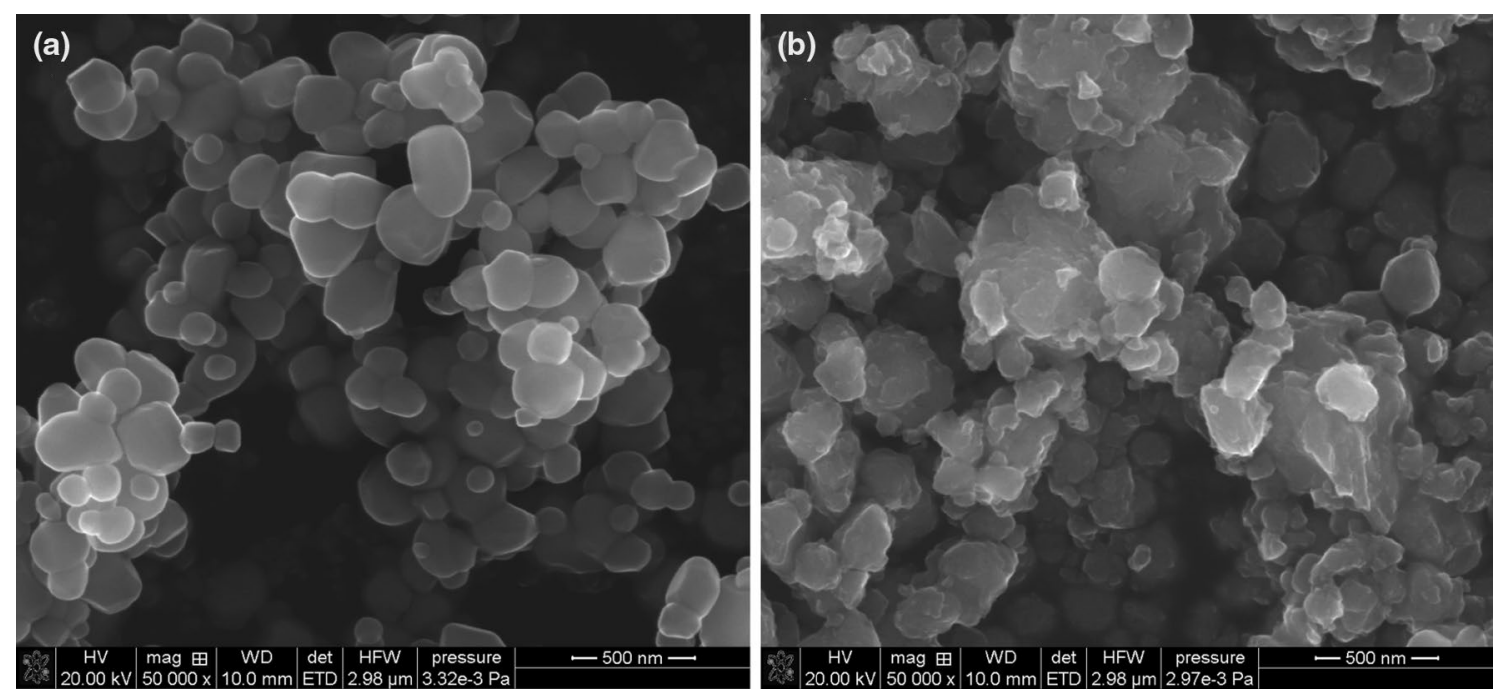

Figure 4 shows the course of changes in the average total pore volume and that of macropores for all mechanochemically modified materials. These data were obtained on the basis of filling the material pores with methanol. As follows from the course of the curves, the mechanochemical treatment causes the reduction of the studied parameters. The tendency is the same for all samples. With the increase mill rotation speed, the total pore volume $\mathrm{V}_{\text {total }}$ and the volume of macropores $\mathrm{V}_{\text {macro }}$ decrease (Fig. 4).

Fig. 3 SEM pictures $\mathrm{TiO}_{2}$ after MChT at 300 (a) and 700 (b) rpm for $1 \mathrm{~h}$ 


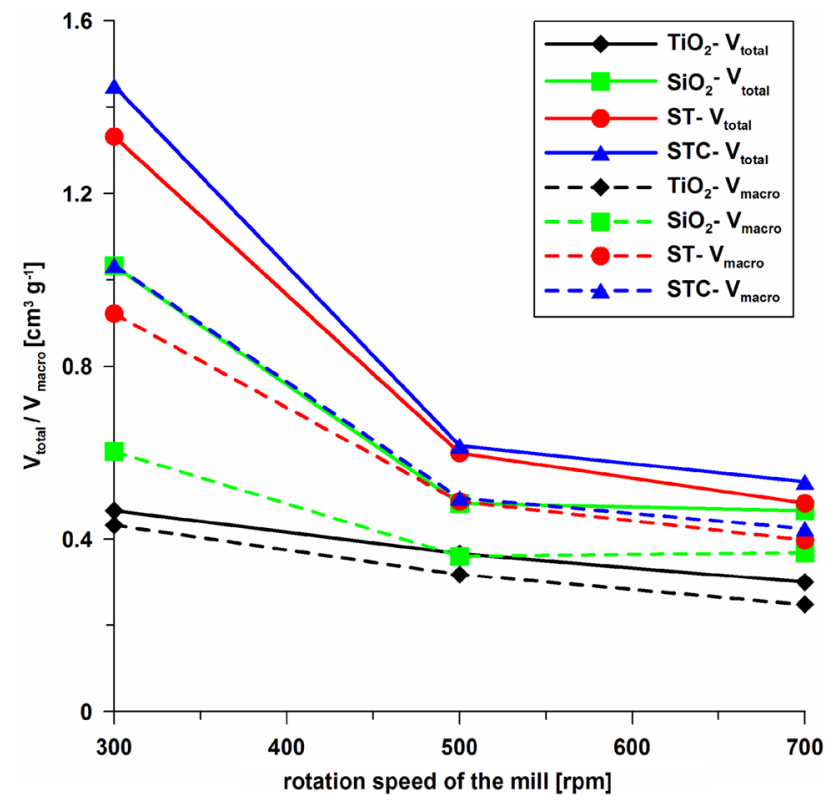

Fig. 4 Exemplary changes in the total pore volume and that of macropores depending on the speed of mill rotation

\subsection{FT-IR/PAS analysis}

In order to have a better insight into the structure of synthesized materials, infrared spectroscopy was used (FT-IR, Fourier transform infrared spectroscopy) and more precisely, photoacoustic spectroscopy (FT-IR/PAS, Fourier transform infrared photoacoustic spectroscopy). This technique has huge advantages over the commonly used transmission technique because it does not require prior sample preparation and is non-destructive. In Fig. 5a $\mathrm{TiO}_{2}$ framework vibrations (below $2000 \mathrm{~cm}^{-1}$ ) and hydroxyl groups bands (3745,
$3670 \mathrm{~cm}^{-1}$-isolated $-\mathrm{OH}$ and hydrogen bonded $-\mathrm{OH} \cdots \mathrm{H}$, respectively) are visible. There are no spectacular changes in the spectra of $\mathrm{TiO}_{2}$ series samples compared to the initial $\mathrm{TiO}_{2}$ material. The only difference is noted in the $-\mathrm{OH}$ stretching range (increase in intensity of the wide band with the maximum at $3390 \mathrm{~cm}^{-1}$ ). This band shows the presence of both $-\mathrm{OH}$ and hydrogen bonded $-\mathrm{OH} \cdots \mathrm{H}$ in the $\mathrm{Ti}-\mathrm{OH}$ structures and/or physically adsorbed water.

Figure $5 \mathrm{~b}$ presents the spectra of $\mathrm{SiO}_{2}$ samples. The peak at approx. $3740 \mathrm{~cm}^{-1}$, visible in all spectra is assigned to the isolated silanol groups $\equiv \mathrm{SiOH}$. The peak at $\sim 3622 \mathrm{~cm}^{-1}$ is responsible for the presence of hydrogen bonded $\mathrm{SiOH} \cdot \cdots^{-} \mathrm{OS}$ groups, and more accurately it indicates the presence of internal hydroxyl groups. The wide band with the maximum at $\sim 3400 \mathrm{~cm}^{-}$shows the presence of both $-\mathrm{OH}$ and hydrogen bonded $-\mathrm{OH} \cdots \mathrm{H}$ in the $\mathrm{Si}-\mathrm{OH}$ structures and physically adsorbed water. The broad, intense bands in the range of $1300-1000 \mathrm{~cm}^{-1}$ can be attributed to the asymmetric stretching vibrations of $\mathrm{Si}-\mathrm{O}-\mathrm{Si}$ bridges, and the peaks at $\sim 795 \mathrm{~cm}^{-1}$ and $\sim 470 \mathrm{~cm}^{-1}$ can be assigned to the symmetric stretching and deformation modes of $\mathrm{Si}-\mathrm{O}-\mathrm{Si}$, respectively. The IR bands observed within $980-910 \mathrm{~cm}^{-1}$ can be assigned to the $\mathrm{Si}-\mathrm{O}-\mathrm{Si}$ stretching vibrations. The band at $972 \mathrm{~cm}^{-1}$ is visible only in the spectrum of the initial silica, but not in the $\mathrm{SiO}_{2}$ series samples spectra, which may indicate that the rotation and energy produced during this process affect the change of silica structure-the band at $972 \mathrm{~cm}^{-1}$ shifts to a lower wavenumber $\left(937 \mathrm{~cm}^{-1}\right)$ for the $\mathrm{SiO}_{2}$ samples.

As you can see the use of high rotation speed (S-500 and $\mathrm{S}-700$ samples) causes a reduction in the quantity of isolated silanol groups $\left(3734 \mathrm{~cm}^{-1}\right)$ while the quantity of hydrogen bonded $\mathrm{SiOH} \cdots^{-}$OSi groups remains practically unchanged $\left(3622 \mathrm{~cm}^{-1}\right)$.
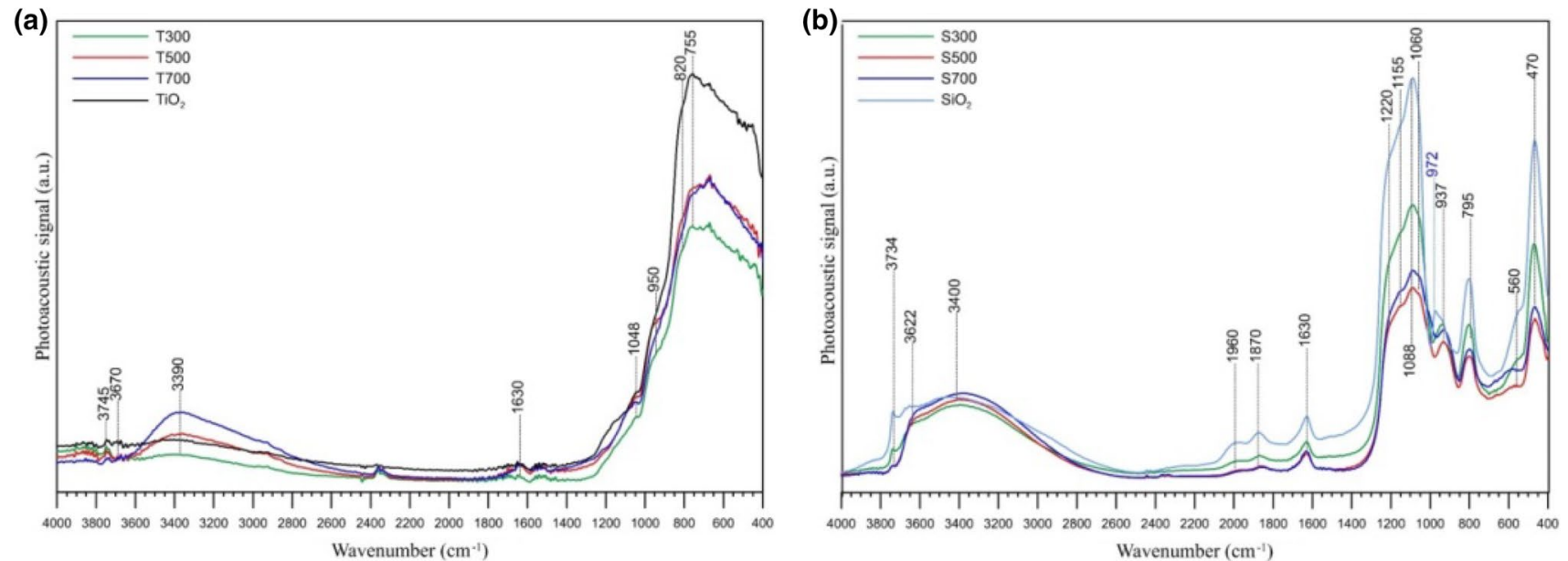

Fig. 5 FT-IR/PAS spectra of T-300, T-500, T-700 and initial $\mathrm{TiO}_{2}$ samples (a) and S-300, S-500, S-700 and initial $\mathrm{SiO}_{2}$ samples (b) in 4000$400 \mathrm{~cm}^{-1}$ range 
In this case there can be also observed the difference in the amount of isolated silanol groups $\equiv \mathrm{SiOH}$-the intensity of the peaks is lower in the case of ST-500 and ST-700 samples (Fig. 6a). The investigations indicate that there can be a relationship between the intensity of the band at $\sim 940 \mathrm{~cm}^{-1}$ and that at $\sim 800 \mathrm{~cm}^{-1}$ (which is responsible for the symmetric $\mathrm{Si}-\mathrm{O}-\mathrm{Si}$ symmetric vibrations). The intensity ratio of $940 / 800 \mathrm{~cm}^{-1}$ is much higher for the silica materials with other ions incorporated into the silica structure. Thus an increase in $940 \mathrm{~cm}^{-1}$ band intensity relative to the band at $800 \mathrm{~cm}^{-1}$ may be evidence of attachment of titania ions into the crystal lattice of silica. In our case, the higher the rotation speed, the higher the $940 / 800 \mathrm{~cm}^{-1}$ ratio. This may show the incorporation of titanium into the silica structure.

In the case of the samples with carbon addition (STC series), the spectra are similar to the previous ones (ST
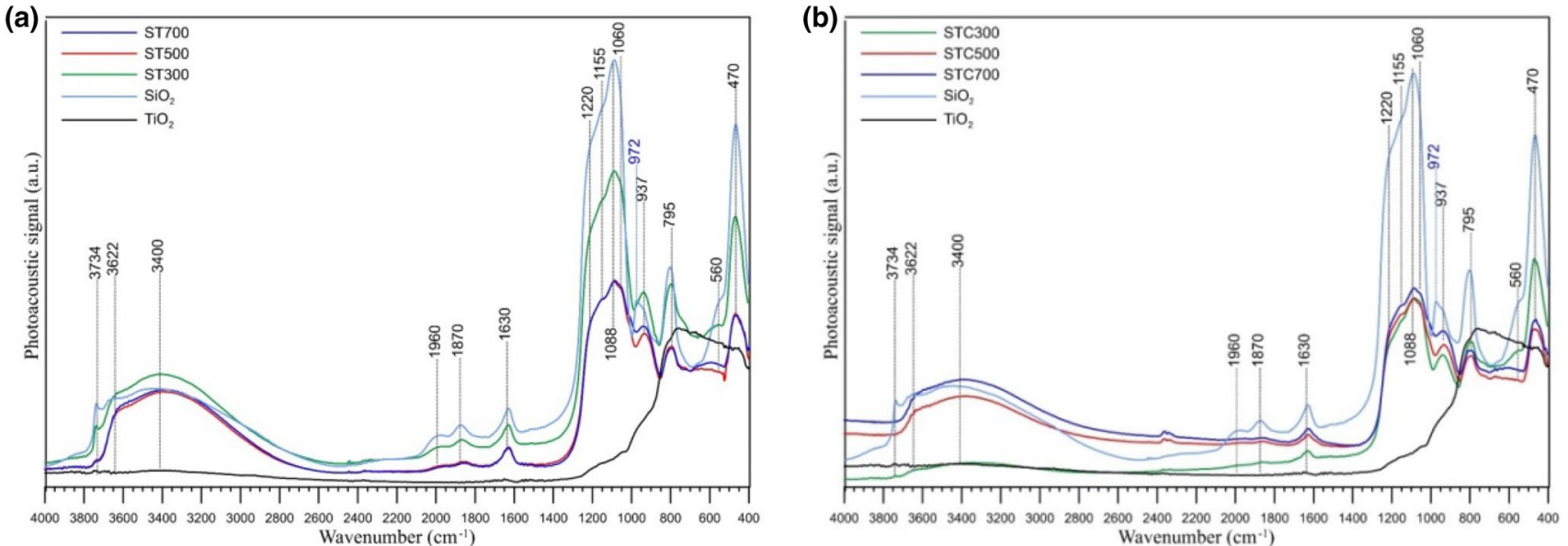

Fig. 6 FT-IR/PAS spectra of ST-300, ST-500, ST-700 and initial $\mathrm{SiO}_{2}$ and $\mathrm{TiO}_{2}$ samples (a) and STC-300, STC-500, STC-700 and initial SiO and $\mathrm{TiO}_{2}$ samples (b) in the $4000-400 \mathrm{~cm}^{-1}$ range
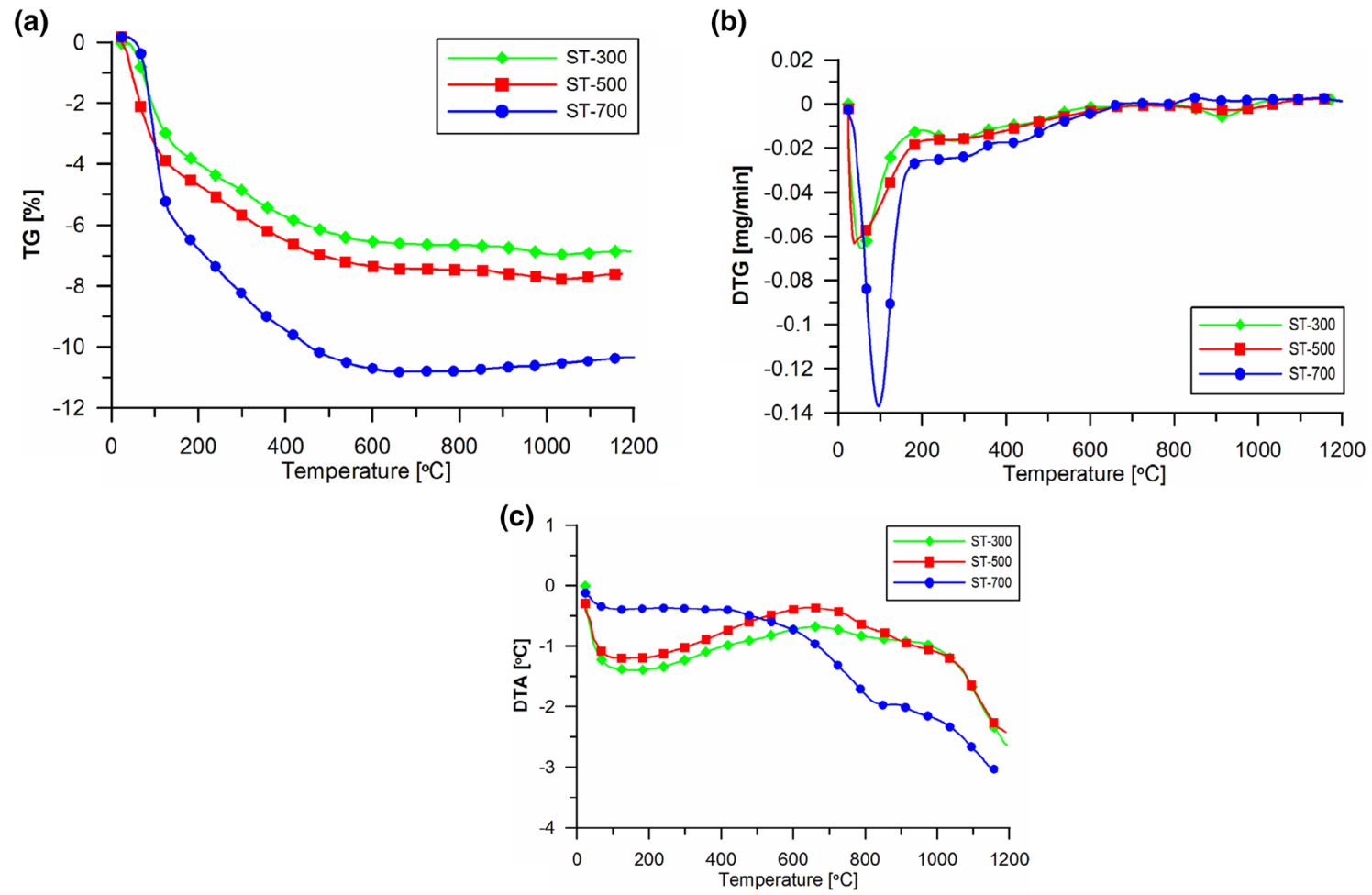

Fig. 7 The course of the TG (a), DTG (b) and DTA (c) curves obtained for the ST composites series 

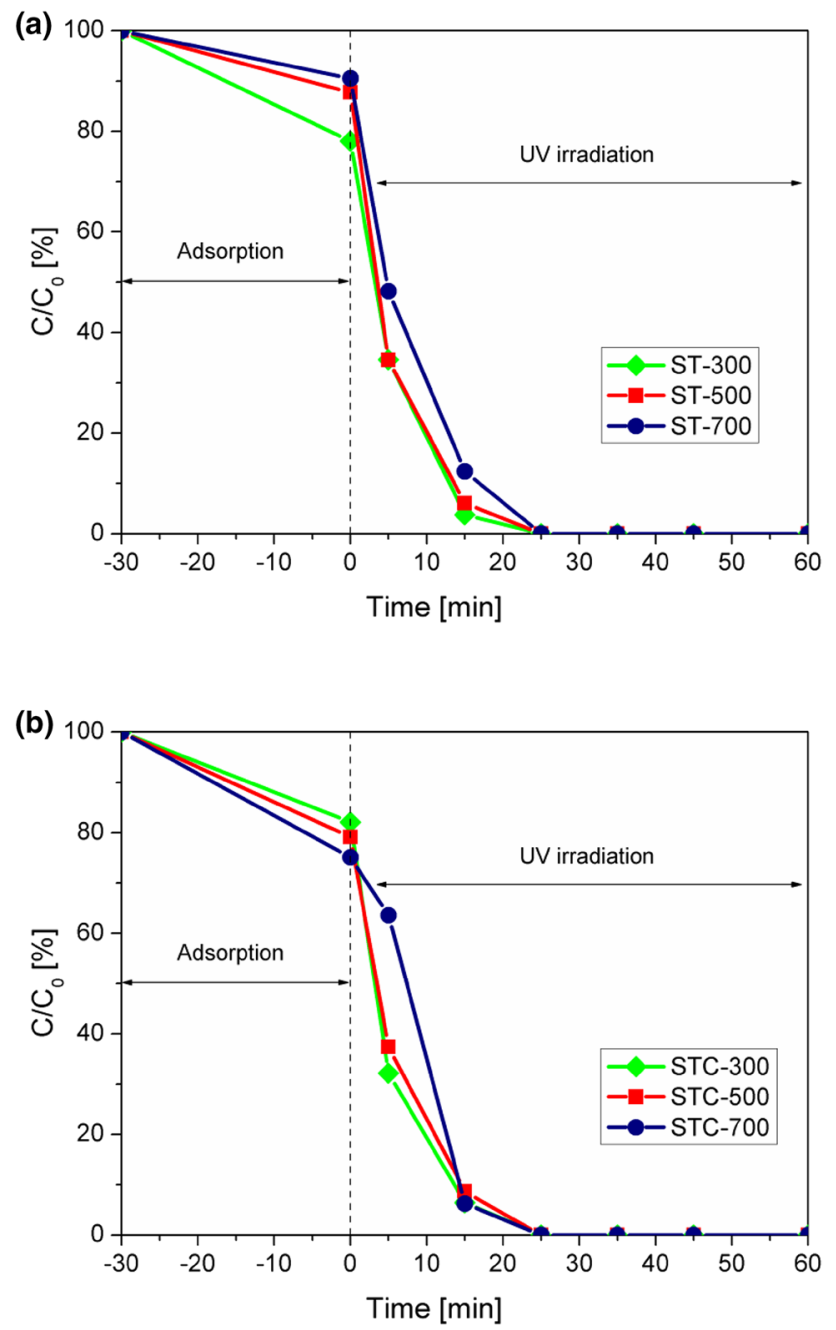

Fig. 8 Adsorption and degradation steps of methylene blue using ST (a) and STC (b) where $\mathrm{C}_{\mathrm{o}}$ is the initial concentration of MB after adsorption

series), but all peaks in the spectra of STC series are of much lower intensity (Fig. 6b). This is probably due to the addition of carbon, which somehow "seals" signals from silica.
Similarly to the ST series, the higher the rotation speed, the higher the $\sim 940 / 800 \mathrm{~cm}^{-1}$ ratio-it may be evidence of titanium incorporation into the silica structure.

\subsection{Thermal analysis}

Application of thermal analysis made it possible to estimate thermal stability of the studied materials. Three series of samples under investigations are individual inorganic oxides ( $\mathrm{S}$ and $\mathrm{T}$ series) or composites (ST series). The initial materials $\left(\mathrm{SiO}_{2}\right.$ and $\left.\mathrm{TiO}_{2}\right)$ are thermally stable. The mass changes during the thermal analysis are a results of desorption of physically bound water $\left(20-200{ }^{\circ} \mathrm{C}\right)$ and surface hydroxyls as well as intraglobular water (above $200{ }^{\circ} \mathrm{C}$ ). The presence of such forms of water was proved by the FTIR investigations. The fourth series contains additionally carbon matter (carbon black, 1\%) but its content is very small and significant effects resulting from its presence are not noticeable. Figure 7 presents the exemplary results of thermal analysis of ST series composites. The course of the TG curves (Fig. 7a) appears to be dominated by the main component of the composite- $\mathrm{SiO}_{2}$. The intensive mass loss is observed in the temperature range $20-200{ }^{\circ} \mathrm{C}(\sim 4-7 \%)$. At a temperature higher than $200{ }^{\circ} \mathrm{C}$ the successive mass loss seems to be dependent on the rotation speed: the higher rotation speed, the grater mass loss. These observations indicate that MChT introduces larger amounts of hydroxyl groups into the composite structure. This is confirmed by the courses of DTG (Fig. 7b) and DTA (Fig. 7c) curves.

\subsection{Photocatalytic characteristics}

For all series of materials including $\mathrm{TiO}_{2}$ (T, ST and STC series) the photocatalytic investigations were carried out. During the measurements the initial adsorption of the dye on the catalyst was observed within the first $30 \mathrm{~min}$. In the case of $\mathrm{TiO}_{2}$ series the adsorption values were $4-21 \%$. For the $\mathrm{SiO}_{2}$ based materials (ST and STC) the adsorption was higher due to silica contribution to the composite structure
Fig. 9 Decomposition rate of methylene blue using $\mathrm{TiO}_{2}$ (a) and ST (b)

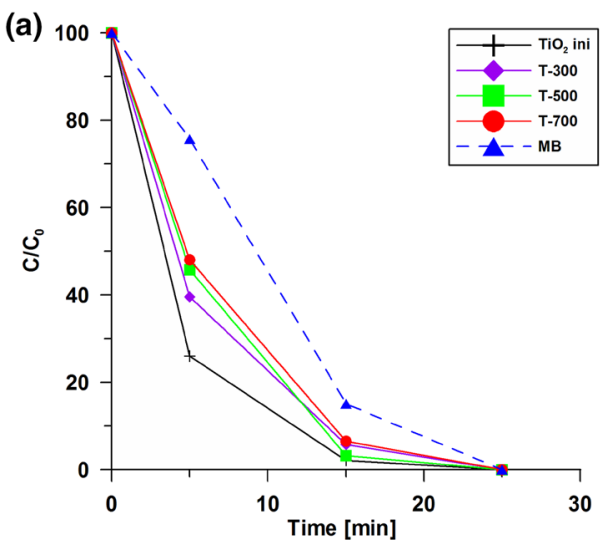

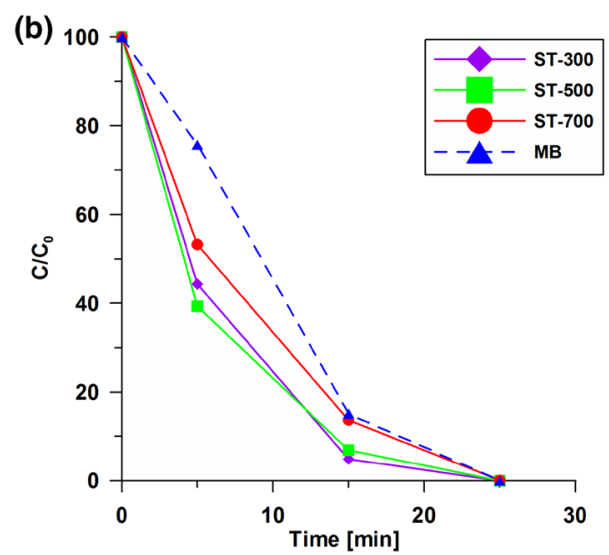


(Fig. 8a, b). Generally, the increase of the rotation speed causes the decrease of structural parameters, which limits the adsorption, but the addition of carbon black causes higher adsorption for the STC series (Fig. 8b), than for the ST series (Fig. 8a). The exemplary adsorption values are 9.5\% for ST-700 (Fig. 8a) and 25\% for STC-700 (Fig. 8b).

The investigation results show that the mechanochemical treatment worsens dye degradation efficiency (Fig. 9a, b). The course of the curves in Fig. 9a shows that the increase in the rotation speed reduces effectiveness of $\mathrm{TiO}_{2}$ as a photocatalyst in the range of UV radiation in the case of all series. Total degradation of the dye was observed after about 20 min. However, the attention should be paid to comparable degradation processes using pure $\mathrm{TiO}_{2}$ (Fig. 9a) and composite materials with a much lower content of this photocatalyst (only 5\%, Fig. 9b).

\section{Conclusions}

We have investigated structural, thermal, and photocatalytic properties of composite materials containing $\mathrm{SiO}_{2}, \mathrm{TiO}_{2}$ and carbon black as a carbon source. The influence of the speed of mechanochemical treatment on these parameters was analyzed. It was shown that mechanochemical treatment allows preparation of composite materials with new structural properties. Increasing the rotation speed reduces the specific surface area $\left(\mathrm{S}_{\mathrm{BET}}\right)$ and the pore volume $\left(\mathrm{V}_{\mathrm{p}}\right)$ of $\mathrm{S}, \mathrm{ST}$ and STC series of composite materials. Only in the case of $\mathrm{TiO}_{2}$ the specific surface area increased slightly. The increase in the rotation speed during the mechanochemical treatment resulted in the increasing bulk density of the tested samples. Thermal analysis showed significant thermal stability of the obtained materials. Up to $200{ }^{\circ} \mathrm{C}$ desorption of physically bound water took place whereas the release of surface hydroxyl groups and intraglobular water, especially from the surface of $\mathrm{SiO}_{2}$-based materials, was observed at a higher temperature. The photocatalytic tests results indicate that the mechanochemical treatment does not improve photocatalytic activity of the studied materials in relation to methylene blue in the UV range.

Open Access This article is distributed under the terms of the Creative Commons Attribution 4.0 International License (http://creativeco mmons.org/licenses/by/4.0/), which permits unrestricted use, distribution, and reproduction in any medium, provided you give appropriate credit to the original author(s) and the source, provide a link to the Creative Commons license, and indicate if changes were made.

\section{References}

Anastas, P.T., Kirchhoff, M.M.: Origins, current status, and future challenges of green chemistry. ACC Chem. Res. 35(9), 686-694 (2002). https://doi.org/10.1021/ar010065m

Anderson, C., Bard, A.J.: Improved photocatalytic activity and characterization of mixed $\mathrm{TiO}_{2} / \mathrm{SiO}_{2}$ and $\mathrm{TiO}_{2} / \mathrm{Al}_{2} \mathrm{O}_{3}$ materials. J. Phys. Chem. B. 101(14), 2611-2616 (1997). https://doi.org/10.1021/ jp9626982

Barret, E.P., Joyner, L.G., Halenda, P.P.: The determination of pore volumes and area distributions in porous substances. J. Am. Chem. Soc. 73(1), 373-380 (1951)

Carneiro, J.O., Azevedo, S., Fernandes, F., Freitas, E., Pereira, M., Tavares, C.J., Lanceros-Méndez, S., Teixeira, V.: Synthesis of iron-doped $\mathrm{TiO}_{2}$ nanoparticles by ball-milling process: the influence of process parameters on the structural, optical, magnetic, and photocatalytic properties. J. Mater. Sci. 49(21), 7476-7488 (2014)

Chong, M.N., Jin, B., Chow, C.W., Saint, C.: Recent developments in photocatalytic water treatment technology: a review. Water Res. 44(10), 2997-3027 (2010)

Fu, X., Clark, L.A., Yang, Q., Anderson, M.A.: Enhanced photocatalytic performance of titania-based binary metal oxides: $\mathrm{TiO}_{2} / \mathrm{SiO}_{2}$ and $\mathrm{TiO}_{2} / \mathrm{ZrO}_{2}$. Environ. Sci. Technol. 30(2), 647-653 (1996). https://doi.org/10.1021/es950391v

Fu, H., Zhang, L., Yao, W., Zhu, Y.: Photocatalytic properties of nanosized $\mathrm{Bi}_{2} \mathrm{WO}_{6}$ catalysts synthesized via a hydrothermal process. Appl. Catal., B. 66(1-2), 100-110 (2006). https://doi. org/10.1016/j.apcatb.2006.02.022

Gao, B., Chen, G.Z., Puma, G.L.: Carbon nanotubes/titanium dioxide $\left(\mathrm{CNTs} / \mathrm{TiO}_{2}\right)$ nanocomposites prepared by conventional and novel surfactant wrapping sol-gel methods exhibiting enhanced photocatalytic activity. Appl. Catal., B. 89, 503-509 (2009). https://doi. org/10.1016/j.apcatb.2009.01.009

Ghorai, T.K., Chakraborty, M., Pramanik, P.: Photocatalytic performance of nano-photocatalyst from $\mathrm{TiO}_{2}$ and $\mathrm{Fe}_{2} \mathrm{O}_{3}$ by mechanochemical synthesis. J. Alloys Compd. 509(32), 8158-8164 (2011). https://doi.org/10.1016/j.jallcom.2011.05.069

Gregg, S.J., Sing, K.S.W.: Adsorption, Surface Area and Porosity, 2nd edn. Academic Press, London (1982)

Hanaor, D.A., Sorrell, C.C.: Review of the anatase to rutile phase transformation. J. Mater. Sci. 46(4), 855-874 (2011)

Haque, E., Jun, J.W., Jhung, S.H.: Adsorptive removal of methyl orange and methylene blue from aqueous solution with a metal-organic framework material, iron terephthalate (MOF-235). J. Hazard. Mater. 185(1), 507-511 (2011). https://doi.org/10.1016/j.jhazm at.2010.09.035

Herrmann, J.M.: Heterogeneous photocatalysis: fundamentals and applications to the removal of various types of aqueous pollutants. Catal. Today. 53(1), 115-129 (1999). https://doi.org/10.1016/ S0920-5861(99)00107-8

Jalalah, M., Faisal, M., Bouzid, H., Ismail, A.A., Al-Sayari, S.A.: Dielectric and photocatalytic properties of sulfur doped $\mathrm{TiO}_{2}$ nanoparticles prepared by ball milling. Mater. Res. Bull. 48(9), 33513356 (2013). https://doi.org/10.1016/j.materresbull.2013.05.023

Kim, S.Y., Lim, T.H., Chang, T.S., Shin, C.H.: Photocatalysis of methylene blue on titanium dioxide nanoparticles synthesized by modified sol-hydrothermal process of $\mathrm{TiCl}_{4}$. Catal. Lett. 117(3-4), 112-118 (2007)

Kucio, K., Charmas, B.: Mechanochemia - metoda syntezy i aktywacji fotokatalizatorów na bazie $\mathrm{TiO}_{2}$. In: M. Drach (eds.) Nowe trendy w fizykochemicznych badaniach granic faz, in polish, pp. 167-179. Polish Chemical Society, Warszawa (2018). ISBN 978-83-60988-25-2 
Li, W.-W., Yu, H.-Q., He, Z.: Towards sustainable wastewater treatment by using microbial fuel cells-centered technologies. Energy Environ. Sci. 7(3), 911-924 (2014). https://doi.org/10.1039/ C3EE43106A

Martinez-de La Cruz, A., Garcia Perez, U.G.: Photocatalytic properties of $\mathrm{BiVO}_{4}$ prepared by the co-precipitation method: degradation of rhodamine $\mathrm{B}$ and possible reaction mechanisms under visible irradiation. Mater. Res. Bull. 45(2), 135-141 (2010). https://doi. org/10.1016/j.materresbull.2009.09.029

Mills, A., Le Hunte, S.: An overview of semiconductor photocatalysis. J. Photochem. Photobiol. A. 108(1), 1-35 (1997). https://doi. org/10.1016/S1010-6030(97)00118-4

Molchanov, V.V., Buyanov, R.A.: Scientific grounds for the application of mechanochemistry to catalyst preparation. Kinet. Catal. 42(3), 366-374 (2001)

Nakata, K., Fujishima, A.: $\mathrm{TiO}_{2}$ photocatalysis: design and applications. J. Photochem. Photobiol. C. 13(3), 169-189 (2012). https ://doi.org/10.1016/j.jphotochemrev.2012.06.001

O’Neill, C., Hawkes, F.R., Hawkes, D.L., Lourenço, N.D., Pinheiro, H.M., Delée, W.: Colour in textile effluents-sources, measurement, discharge consents and simulation: a review. J. Chem. Technol. Biotechnol. 74(11), 1009-1018(1999). https://doi. org/10.1002/(SICI)1097-4660(199911)74:11\%3C1009::AIDJCTB153\%3E3.0.CO;2-N

Pirkanniemi, K., Sillanpää, M.: Heterogeneous water phase catalysis as an environmental application: a review. Chemosphere. 48(10), 1047-1060 (2002). https://doi.org/10.1016/S0045-6535(02)00168 $-6$

Rajeshwar, K., Osugi, M.E., Chanmanee, W., Chenthamarakshan, C.R., Zanoni, M.V.B., Kajitvichyanukul, P., Krishnan-Ayer, R.: Heterogeneous photocatalytic treatment of organic dyes in air and aqueous media. J. Photochem. Photobiol. C. 9(4), 171-192 (2008). https://doi.org/10.1016/j.jphotochemrev.2008.09.001

Rouquerol, J., Baron, G., Denoyel, R., Giesche, H., Groen, J., Klobes, P., Levitz, P., Neimark, A.V., Rigby, S., Skudas, R., Sing, K., Thommes, M., Unger, K.: Recommendations for the characterization of porous solids. Pure Appl. Chem. 66, 1739-1758 (1994)

Van Gerven, T., Mul, G., Moulijn, J., Stankiewicz, A.: A review of intensification of photocatalytic processes. Chem. Eng. Process. 46(9), 781-789 (2007). https://doi.org/10.1016/j.cep.2007.05.012

Wu, J.C.-S., Chen, C.H.: A visible-light response vanadium-doped titania nanocatalyst by sol-gel method. J. Photochem. Photobiol., A. 163(3), 509-515 (2004). https://doi.org/10.1016/j.jphotochem .2004 .02 .007

Wu, Z., Yuan, X., Zhang, J., Wang, H., Jiang, L., Zeng, G.: Photocatalytic decontamination of wastewater containing organic dyes by metal-organic frameworks and their derivatives. ChemCatChem. 9(1), 41-64 (2017). https://doi.org/10.1002/cctc.201600808

Yin, S., Yamaki, H., Komatsu, M., Zhang, Q., Wang, J., Tang, Q., Saito, F., Sato, T.: Preparation of nitrogen-doped titania with high visible light induced photocatalytic activity by mechanochemical reaction of titania and hexamethylenetetramine. J. Mater. Chem. 13(12), 2996-3001 (2003). https://doi.org/10.1039/B309217H

$\mathrm{Yu}$, J., Kudo, A.: Effects of structural variation on the photocatalytic performance of hydrothermally synthesized $\mathrm{BiVO}_{4}$. Adv. Funct. Mater. 16, 2163-2169 (2006). https://doi.org/10.1002/adfm.20050 0799

Yu, J., Zhao, X., Zhao, Q.: Effect of surface structure on photocatalytic activity of $\mathrm{TiO}_{2}$ thin films prepared by sol-gel method. Thin Solid Films. 379(1-2), 7-14 (2000). https://doi.org/10.1016/S0040 $-6090(00) 01542-X$

Yu, J., Zhang, Y., Kudo, A.: Synthesis and photocatalytic performances of $\mathrm{BiVO}_{4}$ by ammonia co-precipitation process. J. Solid State Chem. 182(2), 223-228 (2009). https://doi.org/10.1016/j. jssc.2008.10.021

Zhang, H., Banfield, J.F.: Understanding polymorphic phase transformation behavior during growth of nanocrystalline aggregates: insights from $\mathrm{TiO}_{2}$. J. Phys. Chem. B. 104(15), 3481-3487 (2000). https://doi.org/10.1021/jp000499j

Zhang, K., Guo, L.: Metal sulphide semiconductors for photocatalytic hydrogen production. Catal. Sci. Technol. 3(7), 1672-1690 (2013). https://doi.org/10.1039/C3CY00018D

Zhang, F., Zhao, J., Zang, L., Shen, T., Hidaka, H., Pelizzetti, E., Serpone, N.: Photoassisted degradation of dye pollutants in aqueous $\mathrm{TiO}_{2}$ dispersions under irradiation by visible light. J. Mol. Catal. A: Chem. 120(1-2), 173-178 (1997). https://doi.org/10.1016/ S1381-1169(96)00405-0

Zhang, M., Sheng, G., Fu, J., An, T., Wang, X., Hu, X.: Novel preparation of nanosized $\mathrm{ZnO}-\mathrm{SnO}_{2}$ with high photocatalytic activity by homogeneous co-precipitation method. Mater. Lett. 59(28), 3641-3644 (2005). https://doi.org/10.1016/j.matlet.2005.06.037

Zhao, L., Chen, X., Wang, X., Zhang, Y., Wei, W., Sun, Y., Antonietti, M., Titirici, M.M.: One-step solvothermal synthesis of a carbon@ $\mathrm{TiO}_{2}$ dyade structure effectively promoting visible-light photocatalysis. Adv. Mater. 22(30), 3317-3321 (2010). https:// doi.org/10.1002/adma.201000660

Publisher's Note Springer Nature remains neutral with regard to jurisdictional claims in published maps and institutional affiliations. 